\title{
Gestão participativa da Pousada Uacari: um processo em construção
}

\section{Participatory management at the Uacari Floating Lodge: an ongoing process}

\author{
Nelissa Peralta, Fernanda Sá Vieira, Rodrigo Zomkowski Ozorio
}

\section{RESUMO}

O turismo de base comunitária tem como premissas a promoção da conservação ambiental, valorização da identidade cultural e geração de benefícios diretos para as comunidades receptoras. Entendemos que a consolidação desta atividade, que reivindica o controle efetivo da gestão às populações locais, é fruto de um processo desafiador, onde o fortalecimento e a valorização do capital social são condições para se avançar rumo à autogestão. O objetivo deste artigo é descrever esse processo usando o caso da Pousada Uacari, localizada na Reserva de Desenvolvimento Sustentável Mamirauá. Primeiramente, o artigo analisará temas relacionados à gestão participativa, como os conceitos de participação, capital social, colaboração e conflito e autogestão. Em seguida, descreverá o processo de gestão participativa do empreendimento mencionado, analisando a experiência da Pousada Uacari, como o histórico local de associativismo no contexto do setor de serviços, os fóruns deliberativos de tomada de decisões, e o gerenciamento local da Pousada. Finalmente, as perspectivas da gestão participativa do empreendimento serão analisadas, discutindo suas necessidades principais em termos de capital humano, recursos financeiros, políticos e institucionais.
\end{abstract}

PALAVRAS-CHAVE: Autogestão; Gestão Participativa; Capital Social; Turismo de Base Comunitária; Ecoturismo.

\section{ABSTRACT}

Community-based tourism has as premises the promotion of environmental conservation, strengthening of cultural identity and generation of direct benefits to the host communities. We understand that the consolidation of this activity - which claims an effective management control to local populations - is the result of a challenging process, where the strengthening and enhancement of social capital are conditions to move towards self-management. The objective of this article is to describe this process using the case of Uakari Lodge, located at Mamirauá Sustainable Development Reserve. First, this paper will analyze issues related to participatory management, such as the concepts of participation, social capital, collaboration and conflict and self-management. Then, the article describes the participatory management process of the project, analyzing the experience of the Uakari Floating Lodge, such as the history of local associative organization within the context of the service sector, decision-making forums and local management of the lodge. Finally, the prospects of participatory management of the project will be analyzed, discussing their main needs in terms of human capital, financial, political and institutional resources.

KEYWORDS: Self-Management; Participatory Management; Social Capital; Community-Based Tourism; Ecotourism. 


\section{Introdução}

O turismo de base comunitária é uma atividade que, segundo Sansolo e Burstzyn (2009), tem como componentes principais a promoção da conservação ambiental, valorização da identidade cultural e geração de benefícios diretos para as comunidades receptoras. Tais características são similares ao que era conhecido nos anos 90 como ecoturismo: "ecoturismo envolve viagens a áreas naturais para entender a história natural e cultural do ambiente, não alterando a integridade dos ecossistemas, fazendo com que a conservação dos recursos naturais produza oportunidades de benefícios para as populações locais" (THE INTERNATIONAL ECOTOURISM SOCIETY, 1994, s/p). O ecoturismo serviria como estratégia para diminuir a pressão sobre os recursos naturais (BRANDON, 1995), fornecendo uma fonte de renda alternativa para diversificar a base produtiva de áreas rurais (EAGLES, 1994). A diferença principal entre o ecoturismo e o turismo de base comunitária é que neste último, as populações locais são protagonistas da atividade, possuindo controle efetivo sobre seu desenvolvimento e gestão. Para Russel (2000), para ser considerado turismo de base comunitária a atividade deve preencher três critérios: ter o apoio e participação da população local, o máximo dos seus benefícios econômicos gerados deve ser absorvido pelas populações locais, e a atividade turística deve proteger a identidade cultural e o meio-ambiente.

Essa ênfase na necessidade de protagonismo das populações locais no desenvolvimento do turismo sustentável passou a ser basilar ao se constatar que, sem ela, o turismo tem a tendência de produzir efeitos socioambientais negativos (SIMMONS, 1994). Ou seja, sem envolvimento e controle das comunidades locais no desenvolvimento do turismo, seus benefícios são poucos, raramente se sustentam no longo prazo, enquanto seus efeitos negativos geralmente afetam a população local (MOWFORTH; MUNT, 1998). Para aumentar a viabilidade e a longevidade dos projetos de turismo, seu planejamento deve estar associado ao desenvolvimento socioeconômico local (OKAZAKI, 2008). O envolvimento da população local é visto, portanto, tanto como uma estratégia para a sustentabilidade da atividade, como um direito das pessoas do lugar, os mais afetados pelos resultados, positivos ou negativos do turismo.

A partir dessa constatação, entretanto, a produção acadêmica passou a dedicar grande parte de seus esforços a construir conceitos e modelos, a partir dos quais as experiências de campo eram avaliadas, rotuladas e, não se acomodando às características pré-definidas, muitas vezes desqualificadas. A base comunitária da atividade turística passou, assim, a ser considerada um atributo ou uma condição e não um processo, um objetivo a ser alcançado.

Por outro lado, questionou-se a capacidade de empreendimentos de turismo de base comunitária se manterem financeiramente viáveis ao longo do tempo (MITCHELL; MUCKOSI, 2008) principalmente devido a problemas de acesso aos mercados e a governança coletiva.

Entendemos o turismo de base comunitária como um processo composto de um conjunto de ações com o objetivo de avançar com vistas ao objetivo comum de consolidação de uma atividade ambiental e socialmente 
sustentável, gerando benefícios diretos para as comunidades receptoras e o controle efetivo destas em sua gestão. O objetivo deste artigo é descrever esse processo usando o caso da Pousada Uacari. $O$ artigo está dividido em três partes: a primeira delas fará uma breve revisão da literatura analisando temas geralmente associados à gestão participativa, como os conceitos de participação, capital social, colaboração e conflito e autogestão. Em seguida, o artigo descreve e analisa o processo de gestão participativa do empreendimento, compreendendo uma linha do tempo que se inicia em 1997 até os dias atuais, analisando a experiência de gestão participativa da Pousada Uacari, como o histórico local de associativismo no contexto do setor de serviços, os fóruns deliberativos de tomada de decisões, e o gerenciamento local da Pousada. $\mathrm{Na}$ parte final, nos baseando em entrevistas semiestruturadas com os principais stakeholders, analisamos as perspectivas da gestão participativa, fazendo um diagnóstico atual do empreendimento, suas necessidades principais em termos de capital humano, recursos financeiros, políticos e institucionais.

\section{Conceitos centrais ao turismo de base comunitária}

O termo participação denota uma ação de tomar parte de alguma coisa, de um processo, de uma atividade, de uma decisão. A participação é central no turismo porque não se pode desenvolver a atividade isoladamente. O que entendemos por participação engloba diversos conceitos. Tratando do contexto da inclusão dos cidadãos no planejamento de políticas públicas, Arnstein (1969) refere-se à participação como uma estratégia de redistribuição de poder, que possibilita por sua vez, que a sociedade redistribua benefícios e custos de políticas públicas. Seu trabalho ficou conhecido por expressar uma assertiva simples - a de que existem diferentes níveis de participação social, incluindo níveis de manipulação, de simples consulta e de participação efetiva. A autora equivale participação ao poder de influenciar os processos político-econômicos locais que afetam excluídos ("have-nots").

Outros autores ampliam o conceito de participação abrangendo todos os atores sociais (membros das comunidades, governos, profissionais do setor terciário, e empreendedores) em um processo compartilhado de tomada de decisões (HAYWOOD, 1988). Para desenvolver o planejamento do turismo diversos atores sociais entram em contato, compartilham informações, negociam suas propostas. Redes de colaboração compartilham ativos, sejam eles tangíveis, ativos físicos, ou financeiros ou intangíveis, referentes aos recursos do patrimônio socioambiental. Na gestão do turismo, - envolvimento popular traz importantes vantagens para a iniciativa. Segundo Toledo e Mitraud (2003, p.382), "para o ecoturismo de base comunitária, a participação dos moradores locais é premissa para assegurar a legitimidade, a representatividade e o sucesso nas ações do projeto".

Mas a participação plena em processos de tomada de decisão depende dos meios e recursos dos atores envolvidos (JAMAL; GETZ, 1999). Pequenas comunidades locais muitas vezes enfrentam obstáculos à participação no desenvolvimento do turismo - como ausência de direitos 
fundiários e a ausência do Estado e de políticas públicas, inexperiência com atividades econômicas voltadas para o setor terciário, baixa escolaridade.

Para analisarmos o processo de participação e envolvimento da comunidade no desenvolvimento de uma atividade turística, devemos atentar para as condições e os contextos sociais, políticos e institucionais locais. Esse contexto é crucial para a formação do chamado capital social, diretamente associado aos níveis de engajamento e participação dos cidadãos em processos políticos e econômicos locais. O capital social é o conjunto de redes, as normas de reciprocidade e confiança presentes entre os membros de um mesmo grupo social e entre grupos diferentes em virtude de sua experiência com a interação social e a cooperação (PUTNAM, 1993). O capital social ou a confiança permite que os membros do grupo superem conflitos e disputas que poderiam de outro modo, impedir suas tentativas de cooperação. O capital social é necessário, pois possibilita negociação e diálogo nos processos de tomada de decisão e nos projetos coletivos.

Quando o capital social é escasso, conflitos sociais, ou as disputas por controle ou poder podem ocorrer e impedir a tomada de decisão ou atendimento das metas do grupo. O conflito é um tipo de relação social que ocorre quando a ação dos atores é intencionalmente destinada a contradizer ou resistir aos demais. O conflito social é parte do comportamento humano e pode ter resultados positivos ou negativos, dependendo de como o grupo tende a lidar com o mesmo. Pode promover inovação, criatividade e mudança, pois quando o conflito ocorre, os indivíduos ou os grupos devem posicionar-se mais claramente e procurar novas abordagens ou soluções para os problemas em questão. Por outro lado, os conflitos podem gerar descontentamento e desconfiança e corroer a reciprocidade e o comprometimento dos membros dos grupos com o projeto (RAHIM, 2011).

Embora o conflito social esteja frequentemente presente entre $\mathrm{e}$ dentro dos grupos sociais, quando há capital social e objetivos comuns, o conflito não necessariamente compromete a gestão participativa de empreendimentos. Mas para atingir a autogestão, ou seja, o controle democrático e coletivo dos meios de produção e da gestão pelos trabalhadores (SINGER, 2008), capital social é fundamental.

A autogestão envolve a participação integral dos membros do grupo, o acesso total às informações, o conhecimento dos processos e a autonomia nas decisões (ANTEAG, 2000). Grupos informais, associações e empresas de trabalhadores, organizadas em bases cooperativas e em regime de autogestão tem crescido nos últimos anos (GAIGER, 2003), dentre esses empreendimentos, destacam-se alguns de turismo de base comunitária, como aqueles da Rede Cearense de Turismo Comunitário ${ }^{1}$ e da Central de Turismo Comunitário da Amazônia².

Em empreendimentos de autogestão, os responsáveis pelos diferentes setores têm que cumprir as diretrizes do coletivo. $O$ grau de motivação dos trabalhadores nos empreendimentos de autogestão é reconhecido como uma de suas maiores vantagens: 
Estar trabalhando num negócio que é seu e do qual o trabalhador participa das decisões permite uma motivação maior apesar das adversidades. Por serem proprietários, mas somente quando começam a sentir-se como tal (o que não é trivial), os trabalhadores buscam conhecer melhor o negócio, com reflexos positivos sobre suas atividades (TAUILE; DEBACO, 2004, p.200).

Outra fonte de eficiência desses empreendimentos se refere à transparência na gestão, quando processos formais de monitoramento e acompanhamento da gestão do empreendimento são estabelecidos, proporcionando maior grau de accountability ${ }^{3}$ entre os administradores e demais trabalhadores. "A confiança é um ativo intangível dos mais importantes nesse processo" (TAUILE; DEBACO, 2004).

Entretanto, muitas dificuldades são encontradas por esses empreendimentos. Em termos de qualificação profissional, carência de conhecimentos técnicos e de experiência com o mercado e outras instituições. Para uma gestão democrática do empreendimento é fundamental a apropriação coletiva do conhecimento gerencial (ANTEAG, 2000). Muitas vezes há baixo grau de instrução formal dos trabalhadores e uma fragmentação do conhecimento, ou seja, a retenção da visão integral do empreendimento não é difusa, pois era concentrada nas mãos dos gerentes ou proprietários (TAUILE; DEBACO, 2004).

Outro gargalo é a infraestrutura e equipamentos - ou o capital fixo dos empreendimentos -, que pode comprometer sua rentabilidade no médio prazo. A falta de patrimônio faz com que a empresa nasça com uma estrutura de capital deficiente e que, frequentemente, a necessidade de capital de giro seja superior à sua capacidade de financiá-lo (TAUILE; DEBACO, 2004).

\section{Histórico da gestão participativa da Pousada Uacari}

O modelo de gestão da Pousada Uacari ainda é compartilhado entre o Programa de Turismo de Base Comunitária (PTBC) do Instituto Mamirauá, as comunidades do Setor Mamirauá, onde está localizada a Pousada Uacari, e a associação local de prestadores de serviço em turismo (AAGEMAM).

A atividade de turismo de base comunitária foi pensada inicialmente como uma atividade econômica alternativa para a unidade conservação, com o intuito de aliar benefícios econômicos e incentivar a conservação dos recursos naturais na região. Mas o turismo (e o setor de serviços em geral) não era uma atividade econômica com a qual as comunidades locais tivessem experiência. Portanto, muitas atividades iniciais estavam voltadas aos esclarecimentos sobre a atividade em si, suas características, o perfil do público, seus possíveis impactos, positivos e negativos, etc.

Antes do desenvolvimento do projeto, consultas preliminares foram realizadas com as comunidades locais. Apesar das consultas serem muito cautelosas para não gerar falsas expectativas (AZEVEDO, 1998), ainda assim houve "alguma confusão com expectativas não realistas sobre 
geração de empregos e a possibilidade de comunidades cobrarem dos turistas pelo acesso a trilhas" (HARRISON; SHANKLAND, 1999). Contudo, as reações locais iniciais foram positivas: as comunidades contribuíram no planejamento e o conhecimento ecológico local foi utilizado no desenho da infraestrutura e desenvolvimento dos roteiros e do produto em geral.

Apesar de haver muito envolvimento das comunidades, parte do planejamento estratégico era responsabilidade da equipe do programa de turismo, que detinha mais conhecimento técnico sobre a atividade. Para obter o apoio e o envolvimento das comunidades locais foi desenhada uma estratégia de aproximação com visitas regulares, participação em todos os eventos promovidos pelo setor (como encontros de setor bimestrais e assembleias).

Após as consultas, a implementação do turismo iniciou-se em 1997, logo após a publicação do plano de manejo da unidade. A estratégia do programa foi de aproximar-se das principais lideranças locais para obter 0 apoio necessário à implementação da atividade. Durante os primeiros dois anos, o grupo se dedicou a realizar o inventário dos atrativos turísticos e o seu zoneamento, a construção de infraestrutura e ao desenvolvimento do produto, e ao treinamento e fortalecimento de habilidades locais, além do desenho de mecanismos de monitoramento. Realizavam-se encontros com comunidades locais para planejamento e avaliação das atividades e para prestação de contas, de forma a compartilhar resultados, desafios e perspectivas.

A princípio foi assumida uma estratégia de soft-opening, onde havia atendimento a uma pequena demanda espontânea de turistas à área. Com essa experiência preliminar de recepção de visitantes, a equipe pôde experimentar o produto a ser oferecido (uma combinação de atividades de turismo de natureza e soft adventure) e mercado a ser buscado dentre os perfis de clientes interessados no produto. Outra vantagem foi 0 envolvimento direto de comunidades locais com a atividade, que possibilitou a definição de etapas de implementação, a discussão detalhada das atividades com as comunidades e a melhor forma de utilização da área para o ecoturismo (AZEVEDO, 1998). Essa interação entre turistas e população local logo no início do projeto esclareceu as intenções dos ecoturistas aos olhos dos residentes, deu experiência prática na prestação de serviços para alguns comunitários, e gerou alguns benefícios econômicos, o que rendeu interesse na atividade por parte de outras comunidades (PERALTA, 2002). A participação na oferta de serviços e os benefícios econômicos diretos foram muito bem aceitos, resultando em grande apoio de algumas das comunidades para o empreendimento. O turismo passou a ser a alternativa econômica que oferecia maior retorno para as comunidades que tinham oportunidade de trabalho com a atividade.

Uma consultoria foi contratada para avaliar a viabilidade econômicofinanceira do projeto de turismo. Os recursos advindos da operação da Pousada, de acordo com a consultoria, não seriam substanciais para financiar pesquisas ou a gestão da unidade: "a contribuição da iniciativa para a sustentabilidade da instituição se dará principalmente através da divulgação a visitantes oficiais, mídia, ecoturistas e comunidade local". 
Com o parecer favorável da consultoria, o financiador internacional, o Department for International Development (DFID) ${ }^{4}$ concordou em apoiar o projeto. O empreendimento recebeu financiamento do DFID para a construção de uma infraestrutura apropriada. Entretanto, este financiamento necessitava de garantias da Sociedade Civil Mamirauá ${ }^{5}$ sobre a gestão do empreendimento, sua viabilidade econômica e a minimização de impactos sociais e ambientais. O financiador do projeto também indicou a necessidade de definição do modelo de repartição de benefícios e do modelo de gestão do empreendimento para a continuidade do projeto. As propostas dos consultores contratados pelo financiador são apresentadas a seguir (Quadro 1).

Quadro 1: As propostas dos consultores contratados.

Table 1: Proposals of contracted consultants.

\begin{tabular}{|c|c|c|c|c|}
\hline $\begin{array}{l}\text { Tipo de participação de } \\
\text { benefícios e justificativa }\end{array}$ & Favorecidos & Pagamentos & $\begin{array}{c}\text { Acordos } \\
\text { institucionais }\end{array}$ & Desvantagens \\
\hline $\begin{array}{l}\text { 1.Indenização pela } \\
\quad \text { presença do } \\
\quad \text { empreendimento na } \\
\quad \text { área } \\
\text { Pagamento pode ser } \\
\text { considerado como } \\
\text { investimento, incentivando } \\
\text { o apoio da comunidade } \\
\text { para o empreendimento } \\
\text { durante os estágios iniciais } \\
\text { críticos antes que seja } \\
\text { alcançado um fluxo de } \\
\text { caixa positivo. }\end{array}$ & $\begin{array}{l}\text { Comunidades } \\
\text { do Setor } \\
\text { Mamirauá }\end{array}$ & $\begin{array}{l}\text { Ano } 1 \\
\text { Taxa per capita de } \\
\text { acordo com } \\
\text { número de turistas } \\
\text { Com base na } \\
\text { receita } \\
\text { R } \$ \text { per capita } \\
\text { (1999) }\end{array}$ & $\begin{array}{l}\text { Acordo Setorial } \\
\text { Fundo para o } \\
\text { Setor }\end{array}$ & $\begin{array}{l}\text { Pagamento com } \\
\text { base na receita } \\
\text { produzirá } \\
\text { crescimento nos } \\
\text { custos variáveis }\end{array}$ \\
\hline $\begin{array}{l}\text { 2.Pagamento pelo uso dos } \\
\text { recursos cênicos da } \\
\text { reserva aos quais os } \\
\text { comunitários tem } \\
\text { direito de posse }\end{array}$ & $\begin{array}{l}\text { Todas as } \\
\text { comunidades } \\
\text { da Reserva }\end{array}$ & $\begin{array}{l}\text { Ano } 1 \\
\text { Taxa percentual } \\
\text { na renda } \\
\text { produzida } \\
\text { Com base na } \\
\text { receita } \\
5 \% \text { da renda }\end{array}$ & $\begin{array}{l}\text { Acordo entre } \\
\text { residentes e } \\
\text { usuários e SCM } \\
\text { durante fórum da } \\
\text { AG } \\
\text { Fundo Social } \\
\text { para } \\
\text { comunidades da } \\
\text { Reserva }\end{array}$ & Como acima \\
\hline $\begin{array}{l}\text { 3.Empreendimento } \\
\quad \text { financiará o manejo da } \\
\quad \text { Reserva e } \\
\quad \text { comunidades serão } \\
\text { sócias do } \\
\text { empreendimento. } \\
\text { Para exigir que as } \\
\text { comunidades esperem } \\
\text { determinado nível de } \\
\text { lucros, antes de receberem } \\
\text { benefícios deve-se seguir o } \\
\text { princípio da participação na } \\
\text { gestão estratégica da } \\
\text { operação (através de } \\
\text { assentos no Conselho, } \\
\text { etc.). }\end{array}$ & $\begin{array}{l}\text { A unidade de } \\
\text { conservação }\end{array}$ & $\begin{array}{l}\text { Ano 3: Lucro } \\
\text { operacional } \\
\text { Ano 5: Lucro } \\
\text { operacional } \\
\text { menos provisão } \\
\text { de capital de giro }\end{array}$ & $\begin{array}{l}\text { Comitê de } \\
\text { representantes } \\
\text { das } \\
\text { comunidades e } \\
\text { SCM. }\end{array}$ & $\begin{array}{l}\text { Lucros partilhados } \\
\text { quando alcançarem } \\
\text { nível razoável para } \\
\text { o sucesso do } \\
\text { empreendimento e } \\
\text { demorará para que } \\
\text { as comunidades } \\
\text { desenvolvem o } \\
\text { sentimento de } \\
\text { propriedade do } \\
\text { empreendimento. }\end{array}$ \\
\hline
\end{tabular}

Fonte: Harrison e Shankland (1999). Source: Harrison e Shankland (1999). 
Para os consultores, ainda levaria tempo para que estruturas legítimas e eficazes de representação das comunidades fossem desenvolvidas. Portanto, um período de três ou cinco anos antes da distribuição dos lucros não seria problema para instaurar os arranjos necessários para o sistema de reparticipação de benefícios do empreendimento. No entanto, fazer as comunidades locais investirem seu tempo e trabalho nas atividades de planejamento e desenvolvimento de ecoturismo no presente por recompensas incertas no futuro, provavelmente não encorajaria forte apoio local para o empreendimento de ecoturismo, especialmente dado o pequeno número de postos de trabalho que a Pousada criaria (HARRISON; SHANKLAND, 1999).

Estava claro que era muito importante que as comunidades desenvolvessem um sentimento de propriedade do empreendimento. Principalmente depois de uma grande invasão de pescadores urbanos à área no ano de 2002, essa necessidade se mostrou mais premente. Sem o total apoio das comunidades locais, seria inviável prosseguir com as atividades de ecoturismo no setor. Mas era preciso fortalecer o capital social entre os grupos (comunidades locais, associação de prestadores de serviços e organização não-governamental) para firmar as relações de confiança e reciprocidade necessárias para o diálogo contínuo e as tomadas de decisão. A participação nos lucros foi um desses meios. Optou-se por uma mescla das três opções acima no modelo de repartição de benefícios. Ou seja, apenas as comunidades do setor mais próximo à Pousada Uacari, o setor Mamirauá, seriam sócias do empreendimento e teriam participação nos lucros e na gestão estratégica da operação. Isso se justificou porque a consultoria chegou à conclusão que o empreendimento não teria demanda suficiente para gerar lucros para partição entre as comunidades de toda a unidade de conservação. Além do mais, as comunidades que investiam seu tempo, seu território e trabalho no empreendimento - as comunidades do setor Mamirauá - seriam aquelas mais aptas a compartir os benefícios, já quem compartilhavam também os riscos e os ônus do empreendimento.

Ao final de 2002, já havia sido definida como seria a partição de um superávit do empreendimento: $50 \%$ seriam destinados à atividade de proteção ambiental da área do Setor Mamirauá e $50 \%$ a projetos de desenvolvimento comunitário das comunidades locais. A aplicação dos excedentes na proteção ambiental da área se deveu a um entendimento de que as bases da atividade de ecoturismo eram seus atrativos naturais. Portanto, a atividade deveria investir na proteção ambiental para garantir sua própria sustentabilidade em longo prazo. Além disso, defendia-se que o investimento em ações de proteção ambiental traria benefícios indiretos às comunidades em termos de aumento de recursos naturais importantes para a sobrevivência da população, como o pescado. Ao apresentar essa proposição às comunidades, a equipe obteve o apoio das lideranças locais que estavam diretamente ligadas ao sistema de proteção ambiental da área, o que foi fundamental, pois nem todos os membros das comunidades locais concordaram com a proposta, principalmente aquelas que não estavam envolvidas com a proteção da área, mas, ao contrário, tendiam a transgredir as normas de uso estabelecidas pelo plano de manejo da unidade e pelas lideranças do setor. 
A partição do superávit do empreendimento entre as comunidades locais favoreceu a apropriação do empreendimento por essas comunidades. A liderança que atuava na coordenação dos trabalhos do setor usou a oportunidade para aproximar aquelas comunidades que se encontravam afastadas dos trabalhos de organização comunitária. Era uma forma de fortalecer o setor como um todo, reaproximar as lideranças e arregimentar aliados para as atividades de proteção ambiental, por exemplo. Essa decisão favoreceu também o envolvimento das demais comunidades com a atividade de ecoturismo e promoveu cada vez mais a relação entre a atividade econômica e a proteção da área. Fortaleceu politicamente o setor, aproximou mais as comunidades da organização setorial, e fortaleceu também a iniciativa de turismo frente a alternativas antagônicas, além de fortalecer a iniciativa de preservação e proteção da área, pois havia uma associação entre os benefícios econômicos gerados e a conservação.

Em relação à gestão do empreendimento em si, a experiência corrobora com a afirmação de Tauile e Debaco (2004), pois a partir do momento que as comunidades passaram a sentirem-se proprietárias do empreendimento houve reflexos positivos sobre as atividades de ecoturismo. Além disso, o processo de partição de benefícios aumentou a confiança e a reciprocidade, ou seja, o capital social, entre os grupos que atuavam com o desenvolvimento do projeto. Em momentos de crise do empreendimento como no período de desvalorização do dólar, durante o fechamento do aeroporto, durante a abertura da área para a pesca comercial - a atuação dos trabalhadores da Pousada e o apoio das comunidades locais foi essencial para que o empreendimento se mantivesse de pé.

As discussões sobre qual seria o melhor modelo de organização para a participação dos comunitários na prestação de serviços da Pousada Uacari resultaram no processo de criação de uma associação. Com o apoio de técnicos e consultores, os prestadores de serviço se uniram para a criação de uma associação - a Associação de Auxiliares e Guias de Ecoturismo de Mamirauá (AAGEMAM) - que atualmente ainda presta serviços a Pousada Uacari e está diretamente envolvida na gestão do empreendimento. Criada oficialmente em 03 de junho de 2000, a AAGEMAM é uma sociedade de natureza civil, sem fins lucrativos, formada inicialmente apenas por membros de comunidades locais e atualmente já permitindo a associação de moradores das sedes municipais ${ }^{6}$.

À medida que o fluxo de ecoturistas aumentava, aumentavam também as oportunidades de prestação de serviços e de venda de produtos agrícolas e artesanais. Inúmeros eventos de capacitação envolvendo a população local e os técnicos do programa buscavam obter maior qualidade nos serviços turísticos. Aqueles que se envolviam mais diretamente com a atividade (seja através da prestação de serviços ou da venda de produtos) a apoiavam também mais diretamente. Entretanto, devido ao fluxo ainda baixo de turistas, os benefícios econômicos ainda não eram altos e estavam concentrados em um pequeno número de famílias (cerca de trinta famílias no ano de 2002). Procurava-se distribuir ao máximo os benefícios econômicos através de diversas estratégias, entre elas um sistema de rodízio de prestadores de serviços, para que todos os associados tivessem oportunidade de ao menos uma vez ao mês prestar serviços na pousada. 
Outra estratégia buscada foi privilegiar a compra de pescado e produtos agrícolas locais no abastecimento da cozinha da pousada. Entretanto, isso nem sempre era possível, devido a problemas logísticos, no transporte, na comunicação e na garantia da oferta de produtos. A partir de 2004 a gerência da Pousada foi assumida por um morador local, o que favoreceu o aumento da distribuição de benefícios econômicos diretos às comunidades locais por meio da compra de produtos.

Outra questão pendente ao início do projeto se referia aos mecanismos de gestão, que garantissem geração de receita adequada, otimização de benefícios e minimização de impactos sociais e ambientais negativos. A modalidade de gestão deveria garantir elevados padrões profissionais em um mercado muito competitivo e potencialmente lucrativo, e ainda assim permanecer casada com um forte ethos de desenvolvimento social, equilibrando benefícios sociais e ambientais, com a geração de lucros.

Existiam à época três opções i) operação e gerenciamento realizado pela Sociedade Civil Mamirauá; ii) a terceirização da iniciativa para uma empresa privada; iii) criação de ONG subsidiária à Sociedade Civil Mamirauá. Segundo o relatório da consultoria do DFID, a SCM enxergava que seu papel no desenvolvimento do ecoturismo seria lançar, implementar a nova iniciativa, mas não gerenciá-la no médio ou longo prazo. De fato a terceira opção foi a mais favorecida por financiadores e pela equipe do programa na época:

a terceira opção teria uma maior autonomia, responsabilidade e flexibilidade do que a SCM em termos de gestão do dia-a-dia, e ainda assim, permitiria que a SCM mantivesse algum controle sobre a direção do empreendimento e sua missão. Deve criar profissionalismo através de sua capacidade de recrutar e recompensar um gerente de alto calibre, e poderá desenvolver parcerias com o setor privado, bem como as comunidades locais. Como todos os lucros seriam reinvestidos na comunidade, pesquisa ou trabalho de conservação, não há necessidade que seja uma empresa comercial, registrando-a como de utilidade pública, ela poderá receber doações e será isenta de alguns impostos (HARRISON; SHANKLAND, 1999).

As discussões sobre qual seria o modelo de gestão foram iniciadas em 1999 e uma das propostas foi a criação de uma organização não governamental, sem fins lucrativos, de direito privado, dotada de personalidade jurídica autônoma, para a gestão do empreendimento (AZEVEDO, 1998). Outra proposta era a terceirização do empreendimento, prevendo-se garantias em contrato de cessão. Entretanto, esta última proposta não era bem vista pela equipe da SCM e por financiadores porque apresentava desvantagens. Como empresa privada, seria passível de impostos sobre os lucros e sobretaxas sobre os salários; poderia se submeter ao risco de especulação em detrimento dos compromissos sociais e ambientais locais; teria controle limitado sobre a gestão ou propriedade por 
parte da SCM ou comunidades locais, em termos de cumprimento dos objetivos estratégicos de conservação e desenvolvimento social.

Em 2001 houve a criação de uma Organização Social - o Instituto de Desenvolvimento Sustentável Mamirauá - que viria a substituir a Sociedade Civil Mamirauá na gestão dos projetos de desenvolvimento e conservação implementados inicialmente pela Sociedade Civil Mamirauá, com recursos financeiros do DfID. O Instituto de Desenvolvimento Sustentável Mamirauá estabeleceu um contrato de gestão com o Ministério da Ciência, Tecnologia e Inovação, onde o ministério repassaria recursos financeiros para a execução de atividades de pesquisa e assessoria técnica. Houve um contrato de cessão entre SCM e IDSM, onde a primeira cedia a infraestrutura para a segunda organização. Embora a propriedade de equipamentos que faziam parte da infraestrutura da Pousada Uacari fosse formalmente da Sociedade Civil Mamirauá e Instituto Mamirauá, a gestão operacional ficou sendo compartilhada entre este último e as comunidades do setor.

A transferência da propriedade e da gestão da Pousada Uacari, como planejado inicialmente não ocorreu nos anos subsequentes devido a dois problemas principais. Primeiramente devido ao fato de que 0 desenvolvimento completo de infraestrutura não se concluiu até o ano de 2006, com a inauguração do módulo central da Pousada. Segundo porque entre os anos de 2006 e 2007 a Pousada passou por sérios problemas financeiros devido ao fechamento do aeroporto de Tefé e a diminuição da demanda de turistas. Não havia possibilidade de transferência de gestão antes da revitalização do empreendimento e da melhoria das contas, pois o negócio não tinha capital fixo e capital de giro suficiente para garantir sua sustentabilidade.

De qualquer forma, devido ao envolvimento das comunidades na gestão operacional da Pousada Uacari, estas se mantiveram parceiras no projeto. As lideranças comunitárias demonstram preocupação na operação e manutenção do empreendimento. Em 2005 houve queda significativa da receita, resultado atrelado à queda do dólar, que somado aos gastos com a manutenção da Pousada teve como resultado dificuldades financeiras. As lideranças locais apoiaram gastos substanciais na manutenção da infraestrutura e no desenvolvimento do produto com investimentos em trilhas, um equipamento de apoio na floresta, etc. Demonstrando cumplicidade no entendimento e nas decisões sobre a situação financeira, mesmo sem divisão de excedentes naquele ano.

Em 2006 um fórum com os presidentes do Setor Mamirauá foi criado formalmente, advindo da necessidade de envolver as comunidades locais na tomada de decisão, em nível de gerenciamento do negócio, pois eram vistas como stakeholders, ou seja, parceiros do empreendimento tendo que compartilhar benefícios, ganhos, prejuízos e responsabilidades.

Além do compartilhamento de responsabilidade, em alguns momentos da gestão da Pousada as lideranças propuseram soluções criativas para problemas que o empreendimento enfrentava para a manutenção da infraestrutura: como a doação de madeira para a manutenção ${ }^{7}$. Este tipo de solução vem ocorrendo sempre que existe a necessidade de investimentos 
na infraestrutura e que as lideranças julguem importante colaborar com a manutenção da Pousada.

Ao longo do tempo e da experiência com os fóruns deliberativos, as lideranças se posicionaram sobre decisões estratégicas da Pousada, deliberando sobre os investimentos futuros, atuando como auditores da prestação de contas da Pousada, avaliando as estratégias de controle de gastos. A tomada de decisões coletivas e a transparência na gestão favorece a confiança entre os atores sociais. Essa confiança é um ativo intangível dos mais importantes nesse processo (TAUILE; DEBACO, 2004).

\begin{abstract}
Eu acho que a reunião dos presidentes é muito legal, porque nessa reunião eles estão sabendo como está funcionando a pousada, como está o trabalho, como está o andamento dos trabalhadores aqui dentro, o envolvimento deles. Também é bom porque uma parte, é que eles estão ali ajudando, sabendo como resolver, dando opinião e conhecendo. Porque antes, logo que começou, não tinha essa reunião. Depois que começou a reunião com os presidentes, aí os presidentes começaram a se envolver mais, a pedir para as pessoas das comunidades deles que viessem mais participar (Membro da AAGEMAM, entrevista em 14 de Maio de 2014).
\end{abstract}

As comunidades têm total autonomia para deliberação sobre o uso do recurso das comunidades e a participação de cada ator. O fórum é composto por presidentes eleitos de cada uma das comunidades porque são essas pessoas vistas como legítimas para representar as comunidades em fóruns de tomada de decisões. Toledo e Mitraud (2003, p. 393) avaliam que "a participação efetiva dos diferentes segmentos da comunidade, por meio de representantes por eles reconhecidos como tal, é o que confere legitimidade às decisões do grupo, reconhecendo sua pertinência e autoridade nos procedimentos e pessoas".

Os fóruns com os presidentes são uma importante instância para buscar benefícios aos envolvidos na atividade turística, como também é um espaço de diálogo sobre a avaliação e planejamento das atividades de ecoturismo. As reuniões da AAGEMAM também têm um importante papel na gestão do empreendimento, pois são discutidos o gerenciamento e obrigações da Associação e os associados apresentam as demandas referentes ao trabalho, que são posteriormente discutidas em um contexto mais amplo com as lideranças do setor.

Em 2006 os representantes das comunidades no fórum dos presidentes negociaram um acordo com os funcionários da Pousada, onde os mesmos receberiam aumento de salários se cumprissem com metas de diminuição de custos variáveis da operação. No ano de 2007 as lideranças deliberaram sobre a compra de um motor de popa de alto valor, sobre reformas na infraestrutura e compra de uma estrutura para acomodação dos trabalhadores. Tudo isso em um momento sensível, onde as contas ainda se recuperavam. Em 2008 o fórum decidiu afastar uma das comunidades da 
divisão de excedentes, pois a mesma não tinha participado dos encontros e cumprido com os acordos estabelecidos.

Em 2007 o fórum de presidentes criou um Fundo de Assistência para os membros da AAGEMAM. A Pousada Uacari deveria repassar $5 \%$ do valor dos pagamentos de prestação de serviços para que a associação criasse um fundo de ajuda aos seus associados. Os sócios e dependentes teriam acesso ao fundo com atestado médico e assinatura do presidente da comunidade.

Embora a composição do fórum com os presidentes de cada uma das comunidades seja uma fonte de legitimidade na atuação dos mesmos, pois são vistos como os representantes legais das comunidades, essa decisão traz também uma série de problemas. Primeiramente porque os presidentes das comunidades são lideranças políticas legítimas, mas muitas das vezes sem nenhuma experiência ou atuação em turismo. Isso implica na dificuldade das tomadas de decisões e nas dificuldades sobre a apropriação plena das questões técnicas - sendo que muitas vezes não têm condições técnicas de tratar alguns temas. Como mencionado anteriormente, para uma gestão democrática do empreendimento é fundamental a apropriação coletiva do conhecimento gerencial (ANTEAG, 2000). Esse é um grande gargalo da gestão da Pousada Uacari - as habilidades gerenciais estão concentradas nos técnicos do programa e alguns trabalhadores, como a gerente da Pousada, e não estão difusos entre a maior parte dos trabalhadores ou representantes das comunidades.

Outra questão é a rotatividade de membros que compõem o fórum na maior parte das comunidades, as lideranças políticas são trocadas a cada dois anos, o que dificulta a acumulação de experiência dos representantes locais. A descontinuidade na participação dos presidentes é um problema que contribui para a dificuldade na compreensão dos repasses. As lideranças ainda necessitam de mais capacitação técnica sobre os temas que vão deliberar. Os organizadores da reunião devem encontrar metodologias mais adequadas ao público.

Outra questão é a rotatividade dos técnicos do programa. As organizações são formadas por pessoas, portanto a rotatividade de técnicos e representantes comunitários desfavorece a construção do capital social (a confiança e reciprocidade) necessário para o processo de tomada de decisões coletiva e democrática. Em momentos de alta rotatividade, representantes das comunidades questionaram os altos custos com manutenção e a falta da partição dos benefícios e técnicos do programa, por sua vez, questionaram o próprio processo de gestão coletiva.

A queda no número de visitantes de $23 \%$ entre 2009 e 2010 , devido à crise econômica nos países emissores de turistas, provocou questionamentos sobre a viabilidade econômica do empreendimento. Em 2012 foi finalizado um novo Plano de Negócios para a Pousada Uacari (OZORIO; JANER, 2012). Segundo o Plano, seriam necessários maiores investimentos para que a Pousada pudesse se tornar autônoma financeiramente e para que a total transferência de gestão para as comunidades locais pudesse se concluir. 
Buscando estudar experiências de turismo de base comunitária exitosas foi planejado e desenvolvido um evento técnico-científico para debater sobre processos similares de transferência de gestão de empreendimentos de turismo de base comunitária. Dois empreendimentos estiveram presentes: a Posada Amazonas no Peru e Kapawi Ecolodge no Equador.

A Posada Amazonas, de propriedade da comunidade nativa de Infierno com a gestão da operadora Rainforest Expeditions, com contrato em regime de joint venture de 20 anos desde 1996. O contrato define a divisão de lucros para cada participante (60\% para comunidades) e as decisões são consensuais. Há um Comitê de Controle do Ecoturismo, com cinco representantes nativos e a eleição é feita a cada dois anos. O comitê é responsável pelo monitoramento, avaliação a auditoria dos termos do contrato. A comissão audita balanços financeiros, bem como a operação, sempre que solicitado.

O Kapawi Ecolodge no Equador teve gestão compartilhada entre comunidades Achuar e a empresa privada CANODROS S.A. durante onze anos. O processo de transferência de gestão se deu através de um plano de transferência apoiado pela Conservation International do Equador, a Fundação Pachamama e a empresa CANODROS S.A. O plano previu a entrega de uma empresa financeira e legalmente viável, com uma infraestrutura em bom estado. Para isso, 700 mil dólares foram investidos para a restauração do empreendimento entre os anos de 2006 e 2007. Em 2008 foi realizada a transferência de gestão para as comunidades locais. $O$ povo Achuar contratou um profissional de alto calibre para gerenciar a Pousada e a diretoria da empresa é formada por comunidades locais, com um conselho gestor.

Durante o evento, os processos de transferência de gestão foram discutidos principalmente no que se refere às dificuldades e os desafios durante a transferência de gestão dos empreendimentos convidados. Após as discussões definiu-se uma proposta formal por parte dos presentes no Seminário. A proposta foi que a Pousada Uacari deveria ser de propriedade compartilhada entre a Associação local de prestadores de serviço de turismo (AAGEMAM) e as comunidades do Setor Mamirauá. O gerenciamento administrativo, financeiro e operacional da Pousada Uacari seria de responsabilidade da AAGEMAM.

No debate também foram levantadas e consideradas as vantagens e desvantagens da proposta. Como desvantagens, destacaram-se a sobrecarga de deveres e responsabilidades sobre a Associação e o fato de um mesmo grupo executar e supervisionar a gestão da Pousada. Como vantagens destacaram-se a possibilidade do fortalecimento da parceria entre a Pousada e as comunidades locais, com investimentos locais na Pousada; a maior probabilidade de proteção ambiental do território usado pelo turismo, por parte das comunidades locais; a realização das atividades de proteção e vigilância da área em parceria com agentes ambientais comunitários; a possibilidade de auditorias externas à Pousada; a possibilidade de expandir e desenvolver novos produtos e atrativos em áreas de outras comunidades do setor. 


\section{Perspectivas da gestão participativa da Pousada Uacari}

Para entender as perspectivas de continuidade do processo de transferência de gestão da Pousada Uacari foram feitas entrevistas com lideranças locais, trabalhadores da Pousada e técnicos do programa contratados pelo Instituto Mamirauá. O quadro diagnóstico geral é que as pessoas envolvidas acreditam na possibilidade de transferência de gestão no médio e longo prazo (Quadro 2). Para isso, o principal gargalo identificado foi a necessidade de desenvolvimento do capital humano priorizando habilidades gerenciais (financeiro e contábil, marketing e desenvolvimento de produto). Esse plano de capacitação deve ter vários formatos: cursos de longo prazo, intercâmbios, estágios, etc.

Quadro 2: Panorama das habilidades necessárias para o processo de autogestão da Pousada Uacari.

Table 2: Overview of skills needed for self-management at Uakari Lodge.

\begin{tabular}{|c|c|c|}
\hline $\begin{array}{l}\text { Habilidades } \\
\text { gerenciais }\end{array}$ & Como funciona atualmente & Possíveis Estratégias \\
\hline $\begin{array}{l}\text { Gerenciamento } \\
\text { financeiro e } \\
\text { contábil }\end{array}$ & $\begin{array}{l}\text { - O profissional que ocupa o cargo é do } \\
\text { município de Tefé; } \\
\text { - Todas as demandas são encaminhadas aos } \\
\text { departamentos responsáveis do Instituto } \\
\text { Mamirauá; } \\
\text { - O Instituto Mamirauá possui um Estatuto e } \\
\text { Regimento que a Pousada deve seguir; } \\
\text { - A contabilidade é feita por profissionais do } \\
\text { Instituto; } \\
\text { - Um funcionário da Pousada é responsável } \\
\text { pelo gerenciamento dos recursos financeiros, } \\
\text { prestações de contas, emissão de notas ficais, } \\
\text { solicitações de pagamentos a fornecedores, } \\
\text { controle e entradas e saídas; }\end{array}$ & $\begin{array}{l}\text { - Investir no ensino superior dos } \\
\text { comunitários em áreas } \\
\text { administrativas; } \\
\text { - A contabilidade pode ser } \\
\text { terceirizada. } \\
\text { - Promover estágios internos } \\
\text { onde comunitários sejam } \\
\text { coparticipes das funções } \\
\text { gerenciais; }\end{array}$ \\
\hline $\begin{array}{l}\text { Vendas e } \\
\text { marketing }\end{array}$ & $\begin{array}{l}\text { - Atualmente um comunitário ocupa o cargo e } \\
\text { responde pelas vendas da Pousada; } \\
\text { - O marketing não foi incorporado pelo } \\
\text { funcionário, e é realizado por técnico do } \\
\text { instituto. }\end{array}$ & $\begin{array}{l}\text { - Implementar um plano de } \\
\text { marketing pré-definido } \\
\text { aprovado; } \\
\text { - Investir no curso superior dos } \\
\text { comunitários na área de turismo; } \\
\text { - Estabelecer parceria com } \\
\text { empresa de marketing. }\end{array}$ \\
\hline $\begin{array}{l}\text { Desenvolvimento } \\
\text { do produto }\end{array}$ & $\begin{array}{l}\text { - O planejamento e desenvolvimento de novos } \\
\text { produtos é realizado por técnicos do Instituto; } \\
\text { - A implementação de um novo produto deve } \\
\text { ser aprovada em reunião da AAGEMAM. }\end{array}$ & $\begin{array}{l}\text { - Investir no curso superior dos } \\
\text { comunitários na área de turismo; } \\
\text { - Fazer parcerias com projetos de } \\
\text { pesquisa do Instituto Mamirauá } \\
\text { para testar novos produtos. }\end{array}$ \\
\hline $\begin{array}{l}\text { Inglês dos } \\
\text { moradores locais }\end{array}$ & $\begin{array}{l}\text { - Investimentos com aulas de inglês ocorreram } \\
\text { durante os anos de 2002, 2004, } 2005 \text { e 2006; } \\
\text { - Em } 2014 \text { retomou-se a proposta das aulas } \\
\text { através de um fundo arrecadado em uma } \\
\text { campanha de crowdfunding; } \\
\text { - Após a realização do Seminário e } \\
\text { apresentação de outras experiências, o } \\
\text { programa foi reestruturado; } \\
\text { - Aulas ocorrem de segunda à sexta e } 5 \\
\text { comunitários foram selecionados para se } \\
\text { dedicarem integralmente ao aprendizado do } \\
\text { inglês; } \\
\text { - Fornecimento de bolsa-auxílio para os } \\
\text { estudantes com participação da Pousada } \\
\text { Uacari e AAGEMAM. }\end{array}$ & $\begin{array}{l}\text { - O plano deve ser constante; } \\
\text { - A cada ano, novos estudantes } \\
\text { devem ser incorporados e com } \\
\text { dedicação exclusiva para as } \\
\text { aulas; } \\
\text { - As bolsas de estudos devem ser } \\
\text { mantidas e sempre com } \\
\text { participação da AAGEMAM, } \\
\text { fazendo com que haja maior } \\
\text { compromisso nos resultados dos } \\
\text { associados; } \\
\text { - Elaboração de um programa de } \\
\text { voluntariado para o ensino do } \\
\text { idioma; }\end{array}$ \\
\hline
\end{tabular}


Como mencionado acima, a perspectiva dos entrevistados é que as comunidades locais e a associação de trabalhadores sejam os proprietários sócios do empreendimento, e o Instituto Mamirauá continue atuando em parceria até que não haja mais necessidade de assessoria técnica. Entretanto, para a maioria dos entrevistados, a protagonista na gestão do empreendimento deve ser a Associação:

Porque a Associação trabalha aqui na pousada, conhece todo movimento, todo funcionamento, gastos, gerenciamento mesmo, e a vida financeira da pousada. Em termo de gastos principalmente e controle das coisas, como buscar solução para dentro da pousada, a AAGEMAM está mais por dentro dessa situação (Membro da AAGEMAM, entrevista em maio de 2014).

Para os membros da associação o protagonismo desta seria justificado porque apenas os membros da associação teriam o conhecimento necessário do funcionamento da pousada para dar continuidade ao trabalho. Por meio da qualidade dos serviços de seus membros, a Pousada poderia continuar crescendo e trazendo os benefícios para as comunidades.

Para lideranças locais, as comunidades locais devem estar envolvidas diretamente na gestão da Pousada. Embora, ainda tenham receio de assumir a responsabilidade de sua gestão, pois, segundo os mesmos ainda não estariam preparados. Por isso, há uma preocupação da parte de lideranças locais, para que a transferência de gestão seja gradativa e que haja continuidade de apoio do Instituto.

\begin{abstract}
Eu acredito que dentro dessa gestão sempre nós vamos precisar da parceria do turismo, de pessoas de lá [IDSM]. Nós não vamos ficar sozinhos. Temos que ter pessoas lá para nos atender, vamos supor assim, alguém para auxiliar os nossos trabalhos, principalmente nos pontos que podemos estar falhando (Liderança local, entrevista em maio de 2014).
\end{abstract}

Para um dos entrevistados, o nível de gerência operacional rotineira deve ser assumido por profissionais que tenham autonomia para tomar decisões, que pode ser contratado, como no caso de Kapawi. Além disso, parcerias comerciais podem ser firmadas entre a Pousada e outras empresas (Técnico do programa, entrevista em maio de 2014). Outro nível de administração estratégica poderia ser assumido por um conselho deliberativo:

Outro nível de administração funcionaria como um conselho de acionistas de uma empresa, talvez no formato de um Conselho Deliberativo, que fosse composto por representantes da comunidade, da Pousada, do IDSM. Seria importante pensar muito bem no tipo de decisões destinadas a este conselho, na sua composição e na qualificação dos seus membros.

As principais dificuldades serão a definição e o bom desempenho do papel de cada um dos principais atores; falta de confiança e entendimento sobre o processo de transferência dentro dos níveis mais altos de direção do Instituto Mamirauá; a complexidade inerente ao tipo de empreendimento e às suas peculiaridades e, finalmente, a adesão das comunidades locais. 


\section{Conclusões}

A geração de trabalho e renda através do desenvolvimento local e sustentável e com respeito ao meio ambiente é o objetivo em que muitos apostam para substituir a simples maximização de lucros (TAUILE; DEBACO, 2004). Em empreendimentos de turismo de base comunitária, para atingir o objetivo final de autogestão, muitas dificuldades podem ser encontradas. A principal delas é a apreensão da ideia por parte de todos os atores envolvidos que a lógica capitalista de produção e maximização de lucros - na qual os trabalhadores, os mercados, a atividade está envolvida - não é necessariamente o melhor caminho para superação de obstáculos. Valorizar e investir em capital social é a chave para o sucesso de empreendimentos de gestão participativa e de autogestão. A confiança e reciprocidade necessárias para esse tipo de gestão só poderão ser alcançadas com altos níveis de transparência e um compromisso com o diálogo.

Nesse sentido, estes empreendimentos - que têm em sua essência a preocupação central com o protagonismo das comunidades na gestão - devem compreender que a implantação da gestão participativa é um processo, fruto de uma construção gradual e coletiva. E como cada iniciativa está inserida em um contexto específico (geográfico, socioeconômico, ambiental, institucional), é lógico concluir que o tempo de maturação deste processo é relativo. Este entendimento por parte dos atores envolvidos na iniciativa (comunidade, técnicos, financiadores, etc.) é fundamental para se atingir o objetivo desafiador da autogestão.

Ao longo dos seus 16 anos, a iniciativa de turismo de base comunitária Pousada Uacari tem avançado rumo à autogestão, mas entendemos que ainda há um caminho a ser percorrido no que se refere, sobretudo, ao fortalecimento do capital social (que incrementa a participação e amadurece os espaços de tomada de decisão) e ao desenvolvimento das habilidades operacionais e gerenciais dos moradores locais. Entendemos também que o respeito à maturação deste processo é uma condição para se criar bases sólidas que garantam vida longa à iniciativa.

\section{Referências bibliográficas}

ASSOCIAÇÃO NACIONAL DOS TRABALHADORES DE EMPREENDIMENTOS AUTOGESTIONADOS. Autogestão: construindo uma nova cultura de relações de trabalho. São Paulo: ANTEAG, 2000.

ARNSTEIN, S. A ladder of citizen participation. Journal of the American Institute of Planners , 4, pp. 216-224, 1969.

AZEVEDO, A.D. Relatório Anual do Programa de Ecoturismo. Tefé: Sociedade Civil Mamirauá, 1998.

BRANDON, K. Etapas básicas para incentivar a participação local. In: LINDBERG, K.; HAWKINS, D. Ecoturismo: um guia para planejamento e gestão. São Paulo: Editora SENAC, 1995.

EAGLES, P.F. Understanding the Market for Sustainable Tourism. USDA Forest Service. Minneapolis: International Research Station - USDA Forest Service, 1994.

GAIGER, L.I. A Economia Solidária Diante do Modo de Produção Capitalista. CADERNO CRH , 39, pp. 181-211, 2003. 
HARRISON, M.; SHANKLAND, A. Proccess Support consultancy and Social Development Consultancy. London: Department for International Development, 1999.

HAYWOOD, K. Responsible and responsive tourism planning in the community. Tourism Management , 9 (2), pp. 105-118, 1988.

JAMAL, T.; GETZ, D. Community roundtables for tourism-related conflicts: the dialectics of consensus and process structures. Journal of Sustainable Tourism , 7 (3-4), pp. 290-313, 1999.

MITCHELL, J.; MUCKOSI, P. A misguided quest: Community-based tourism in Latin America. (O. D. Institute, Ed.) Opinion. Publication of Overseas Development Institute, 102, 2008.

MOWFORTH, M.; MUNT, I. Tourism and Sustainability: new tourism in the Third World. London: Routledge, 1998.

OKAZAKI, E. A community-based tourism model: its conception and use. Journal of Sustainable Tourism, 16, (5pp. 511-529), 2008.

OZORIO, Z.R.; JANER, A. Community-based ecotourism in the Mamiraua Reserve: Evaluation of Product Quality and Reflections Regarding the Economic and Financial Feasibility of the Activity. UAKARI , 8 (2), pp. 94-114, 2012.

PERALTA, N. Implantação do Programa de Ecoturismo na Reserva de Desenvolvimento Sustentável Mamirauá, AM. OLAM- Ciência e Tecnologia, 2 (2), 2002.

PUTNAM, R. Making Democracy Work. Princeton, NJ: Princeton University Press, 1993.

RAHIM, A.M. Managing Conflict in Organizations (Quarta Edição ed.). New Jersey: Transaction Publishers, 2011.

RUSSEL, P. Community-based tourism. Travel \& Tourism Analyst, 5, pp. 89116, 2000.

SANSOLO, D.; BURSZTYN, I. Turismo de Base Comunitária: potencialidade no espaço rural brasileiro. In: BARTHOLO, R.; SANSOLO, D.; BURSZTYN, I. Turismo de base comunitária: diversidade de olhares e experiências brasileiras. (pp. 142-161). Rio de Janeiro: Letra e Imagem, 2009.

SDS - Secretaria de Meio Ambiente. IN 4/2009. Instrução Normativa №. 4 . Manaus, AM: SDS. 08 de setembro de 2009.

SIMMONS, D. Community participation in tourism planning. Tourism Management, 15 (2), pp. 98-108, 1994.

SINGER, P. Economia Solidária. Estudos Avançados, 62, pp. 289-314, 2008.

TAUILE, J.R.; DEBACO, E.S. Autogestão no Brasil: o salto de qualidade nas políticas públicas. Indic. Econ. FEE , 32 (1), pp. 197-220, maio de $2004 .$.

THE INTERNATIONAL ECOTOURISM SOCIETY. Acesso em Outubro de 2012, disponível em <www.ecotourism.org>. 1994.

TOLEDO, V.; MITRAUD, S. Participação comunitária e parceria. In: S. MITRAUD, Manual de Ecoturismo de Base Comunitária: ferramentas para um planejamento responsável. Brasília: WWF, p. 393, 2003. 


\section{Notas:}

${ }^{1}$ Para mais informações, consulte http://www.tucum.org/oktiva.net/2313/

${ }^{2}$ Para mais informações, consulte http://www.amazoniacomunitaria.org/

${ }^{3}$ Accountability se refere à obrigação de membros de uma organização de prestar contas aos demais integrantes, ou seja, informar e discutir com o grupo o que faz, como faz, por que faz, quanto gasta e o que pretende fazer.

${ }^{4}$ Organização de ajuda internacional britânica.

${ }^{5}$ Organização não governamental que elaborou e implementou o projeto de turismo de base comunitária entre 1997 e 2001

${ }^{6}$ Desde que comprovem alguma relação de parentesco com os moradores da Reserva.

${ }^{7}$ A Instrução Normativa № 4, de 08 de setembro de 2009 (SDS/AM) no seu Artigo $2^{\circ}$ autoriza o manejo sustentável da Reserva Legal para a exploração florestal eventual, sem propósito comercial direto ou indireto, para consumo nas propriedades do agricultor familiar, do empreendedor familiar rural e dos povos e comunidades tradicionais (SDS - Secretaria de Meio Ambiente, 2009).

Nelissa Peralta: Instituto de Desenvolvimento Sustentável Mamirauá, Tefé, AM, Brasil.

E-mail: nelissa@mamiraua.org.br

Link para o currículo Lattes: http://lattes.cnpq.br/6939447320676136

Fernanda Sá Vieira: Instituto de Desenvolvimento Sustentável Mamirauá, Tefé, AM, Brasil.

E-mail: fernanda.sa@mamiraua.org.br

Link para o currículo Lattes: http://lattes.cnpq.br/7300839397572939

Rodrigo Zomkowski Ozorio: Instituto de Desenvolvimento Sustentável Mamirauá, Tefé, AM, Brasil.

E-mail: rodrigo.ozorio@gmail.com

Link para o currículo Lattes: http://lattes.cnpq.br/9662250614426650

Data de submissão: 18 de dezembro de 2014

Data de recebimento de correções: 15 de janeiro de 2015

Data do aceite: 15 de janeiro de 2015

Avaliado anonimamente 